\title{
Statistical analysis of air-conditioning and total load diversity in typical residential buildings
}

\author{
Naja Aqilah Hisham ${ }^{1}$, Sheikh Ahmad Zaki Shaikh Salim², Aya Hagishima ${ }^{3}$, \\ Fitri Yakub ${ }^{4}$, Hafizah Farhah Saipan Saipol ${ }^{5}$ \\ 1,2,4,5Malaysia-Japan International Institute of Technology, University Technology Malaysia, Malaysia \\ ${ }^{3}$ Interdisciplinary Graduate School of Engineering Sciences (IGSES), Kyushu University, Japan
}

\section{Article Info}

Article history:

Received Dec 20, 2019

Revised Mar 7, 2020

Accepted May 7, 2020

\section{Keywords:}

Air-conditioner

Electricity usage

Residential

Statistical analysis

\begin{abstract}
Electricity consumption by air-conditioners in residential buildings significantly affects the electrical grid. The stability of the grid can be improved by a precise prediction of air-conditioning (AC) variations. Therefore, more information about the electricity usage patterns specifically on AC load is important. This paper aims to determine the consumption patterns of $\mathrm{AC}$ and total load through a field measurement of 20 dwellings located in Kuala Lumpur and Selangor. Next, correlation and clustering are employed to identify the relationship between outdoor temperature and AC electricity consumption. The results revealed $75 \%$ of the occupants use the AC almost every day for about five to six hours per day at the rates of $0.93 \mathrm{kWh} /$ day during day time and $3.43 \mathrm{kWh} /$ day during night time. The correlation coefficient between the total daily AC consumption and the mean daily outdoor temperature ranged from -0.1 to 0.48 . The variation of electricity consumption with time shows that $\mathrm{AC}$ electricity consumption increases with the increase of usage time. Lastly, the clustering process of AC usage pattern based on outdoor temperature displayed the uncommon behaviour from dwellings whereby high AC electricity consumption was recorded at low outdoor temperature.
\end{abstract}

This is an open access article under the CC BY-SA license.



\section{Corresponding Author:}

Sheikh Ahmad Zaki Shaikh Salim,

Department of Mechanical Precision Engineering,

Malaysia-Japan International Institute of Technology,

University Technology Malaysia, 54100 Kuala Lumpur, Malaysia.

Email: sheikh.kl@utm.my

\section{INTRODUCTION}

As one of the fast-developing countries, Malaysia depends on fossil fuels such as coal and natural gas to propel most of the infrastructure and to generate electricity. According to the energy commission [1], Malaysia produced about 38000 ktoe for all types of fuel from 1993 to 2013 . Meanwhile, the final energy demand in 2015 recorded a $27 \%$ increase from 40,845 to 51,807 ktoe [2]. However, fossil fuel is a nonrenewable resource which deplete over time. It releases greenhouse gases (GHG) which are responsible for climate change and global warming.

Unlike fossil fuels, renewable energy (RE) provides alternative energy supplies with minimal or zero $\mathrm{CO}_{2}$ emissions. Since Malaysia is a tropical country known for its agricultural industry, biomass, biogas, and solar are the main available RE resources besides hydroelectric [3]. However, the main issue pertaining to $\mathrm{RE}$ is sustaining the generation capacity. For example, solar energy production is influenced by the changing weather and is not always consistent. The power generation of RE can be unstable and does not concur with the demand for electricity. The major constrain is the infrastructure required to store 
the harnessed energy and its distribution [4]. Hence, one way to overcome this issue is to collect more data about the usage patterns of the end user especially on air conditioning (AC) load as it uses more power and influences the load curve significantly. Ranjbar et al., [5] stated that the air-conditioner is the highest contributor to the electricity usage in each dwelling sample, ranging from $28 \%$ to $46 \%$ of the total electricity usage. Various studies were carried out to link the occupant behaviour to the AC load and energy consumption. So far, many studies investigated physical environmental factors such as indoor temperature [6-9] and outdoor temperature $[6,8,10]$. For example, the AC usage pattern of residents in Kansai, Japan indicated that the AC operation rate was $80 \%$ at the outdoor temperature of $36^{\circ} \mathrm{C}$ and the indoor temperature of $27^{\circ} \mathrm{C}$ [6]. The study from Perez et al., [11] mentioned that the precise prediction of $\mathrm{AC}$ variations can improve the stability of the grid.

The precise estimation of stochastic energy consumed by AC influenced by occupant behaviour, is essential to build and operate residential distributed generation systems in association with RE. Therefore, it is necessary to conduct research aiming to determine both $\mathrm{AC}$ and total dwelling's electricity consumption and its relation to the environmental factors such as outdoor and indoor temperature. The occupant behaviour towards the AC consumption may be different depending on the geographical location such as country or region. Thus, in this research, a field measurement of 20 selected dwellings was conducted to record the characteristics and consumption patterns of AC loads in Malaysian typical residential buildings and to determine the relationship between outdoor temperature and the AC electricity consumption.

\section{RESEARCH METHOD}

\subsection{Target dwellings}

Two major urban areas in Malaysia which are Kuala Lumpur and Selangor were selected as the measurement locations. To be specific the measurement was carried out in 19 dwellings from low-cost apartment buildings in Desa Rejang, Kuala Lumpur $\left(3.1900^{\circ} \mathrm{N}, 101.7304^{\circ} \mathrm{E}\right)$ and a two-storey terraced house in Kajang, Selangor $\left(3.0082^{\circ} \mathrm{N}, 101.8084^{\circ} \mathrm{E}\right)$. The dwellings were selected based on a voluntary basis and must be equipped with $\mathrm{AC}$ in one or more room. The number of family members in the selected dwellings ranges from 2 to 9 people. The total and AC electricity consumption of each dwelling were measured. The measured room represents living spaces equipped with frequently used AC's such as the living room (LR), bedroom 1 (BR1), bedroom 2 (BR2), and bedroom 3 (BR3). The dwelling compositions can be summarized into three groups for which $55 \%$ are dual income family, $40 \%$ are single income family, and only $5 \%$ were senior couples.

\subsection{Overview of the measurement}

The measurement profile is shown in Figure 1 such that the dwellings (represented by Dwelling ID) are sorted according to the increasing number of measurement days. Electricity usage of 20 dwellings was successfully measured for a minimum of 52 days to a maximum of 386 days. The total electricity consumption and total AC electricity consumption of all targeted dwellings were measured using the energy-monitoring devices (OWL) as shown in Figures 2(a)-(b), respectively. The details of the installation of the instruments are explained in $[12,13]$. The ACs used in the selected dwellings was different in terms of brand, capacity and cooling mode among others. Although these differences would affect the results, we conducted questionnaire surveys in order to obtain detailed information about the dwellings and the AC used. The survey included number of occupants, dwelling compositions, income, home ownership, monthly electricity consumption and years stay, number of $\mathrm{AC}$, type of room where the $\mathrm{AC}$ is installed, set time for AC, set point temperature, cooling mode, age of AC and energy star of AC.

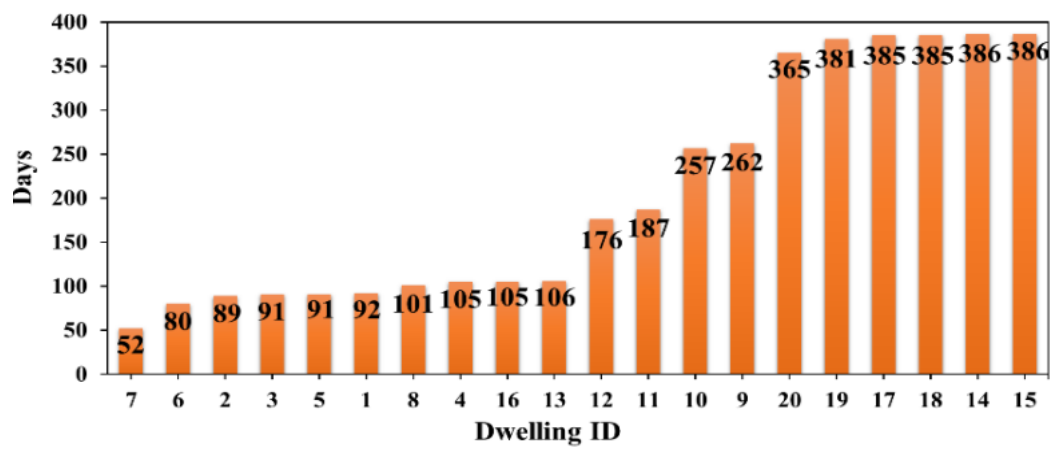

Figure 1. Measurement profile for each dwelling 

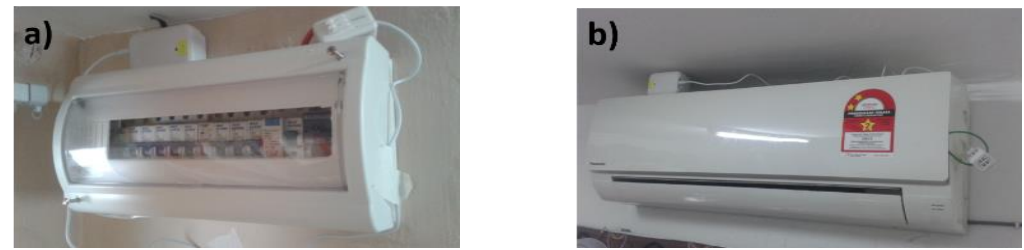

Figure 2. OWL installed at, (a) Circuit breaker, (b) Air-conditioner

\subsection{Cluster analysis}

Cluster analysis is the process of grouping the observations into clusters whereby the objects in the same cluster have high similarity while objects in different clusters have low similarity. Among various clustering methods, K-means is the most widely used method [14-18]. It is capable of clustering a large number of sample quickly and efficiently and highly popular in load curve clustering [19-21]. The K-means method identifies $\mathrm{k}$ number of centroids, then assigns each data point to the nearest cluster while keeping the centroids as small as possible. It uses the Euclidean distance formula as shown in (1) to find the correlation between two objects by examining the root of square differences.

$$
\operatorname{dist}(x, y)=\sqrt{\sum_{i=1}^{n}\left(x_{i}-y_{i}\right)^{2}}
$$

where $x_{i}$ and $y_{i}$ are the attributes of a given object and $i$ varies from 1 to $n$. In this research, the K-means cluster is applied in SPSS to cluster all hourly AC data of each targeted dwelling within the same period recording the outdoor temperature.

Firstly, the number of clusters was specified in advance. The data is standardized and rescaled by using the z-score formula in (2). In this context, $x$ represents the score, $\mu$ represents the mean and $\sigma$ represents the standard deviations. Next, the z-score results were used as the basis for the trace or input cluster. Then the clustering process began by grouping the data within its minimum distance and a data point became part of a cluster if it was the closest from its cluster centre.

$$
Z=\frac{x-\mu}{\sigma}
$$

\section{RESULTS AND DISCUSSION}

\subsection{AC usage frequency}

Figure 3 provides an overview of the ratio of AC usage days to the total measurement days in all 20 targeted dwellings. The data obtained with less than 30 minutes of AC usage in a day were filtered out, while the rest were included for analysis. In Figure 3, the highest ratio was 0.9 which corresponded to 10 dwellings for which the residents used AC almost every day. In addition, Figure 4 shows the daily hours of AC usage for all 20 targeted dwellings. The figure indicates that most of the residents used AC for five to six hours per day. This result is similar to a field survey conducted in China which found that the residents kept the AC running for eight hours per day [22].

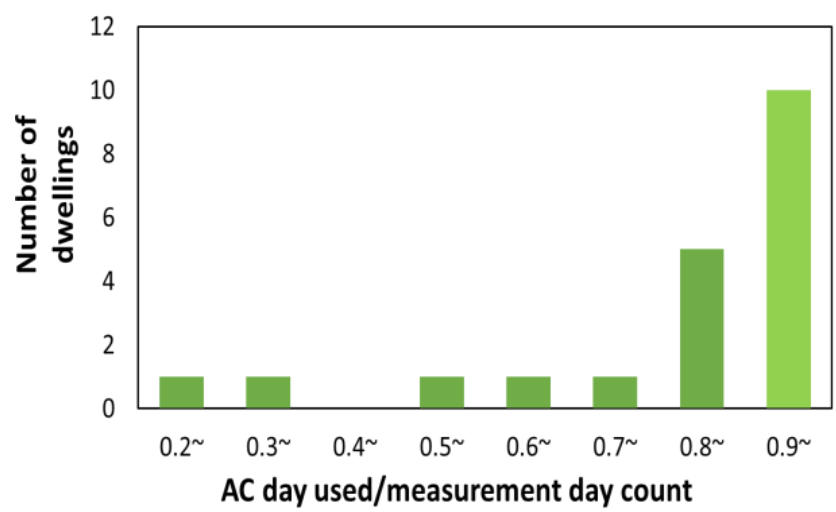

Figure 3. Ratio of AC usage days to total measurement days 


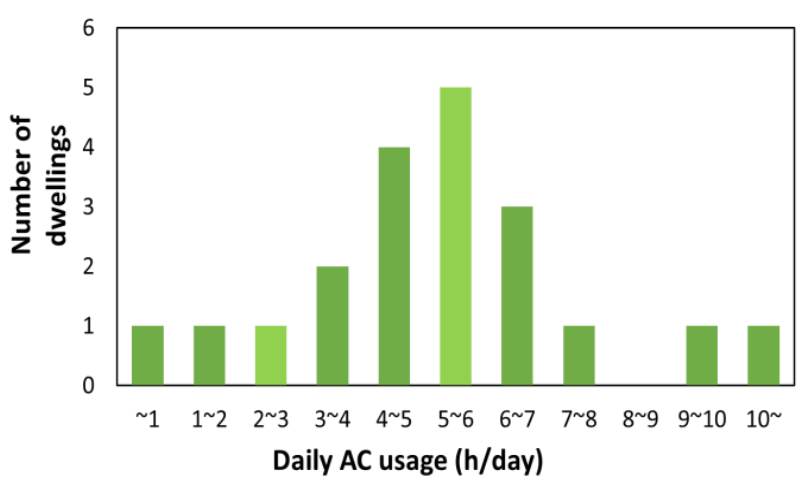

Figure 4. Daily hours of AC usage

\subsection{Total daily and AC usage of each dwelling}

Figure 5 shows the total energy consumption and the total AC energy based on two time slots, day time and night time. The time slot for day time is from 6:00 to 18:00 and for night time is from 18:00 to 6:00. The total energy consumption and the total AC energy consumption from 20 targeted dwellings were shown in Figure 5(a)-(b), respectively. The daily averages of the total energy consumption are $5.4 \mathrm{kWh} /$ day (day time) and $8.4 \mathrm{kWh} /$ day (night time). Meanwhile, the daily average of total AC consumption is much lower which are $0.93 \mathrm{kWh} /$ day (day time) and $3.43 \mathrm{kWh} /$ day (night time). Essentially, the AC energy consumption averages during night time and day time accounted for about $41 \%$ and $17 \%$ of the total energy consumption, respectively was used by $\mathrm{AC}$. This indicates that most of the residents used $\mathrm{AC}$ at night rather than during the day. According to Kubota et al., [23], the detailed daily usage patterns of cooling appliances in Malaysia showed that most of the residents installed AC in their bedrooms to be operated at night when they sleep.
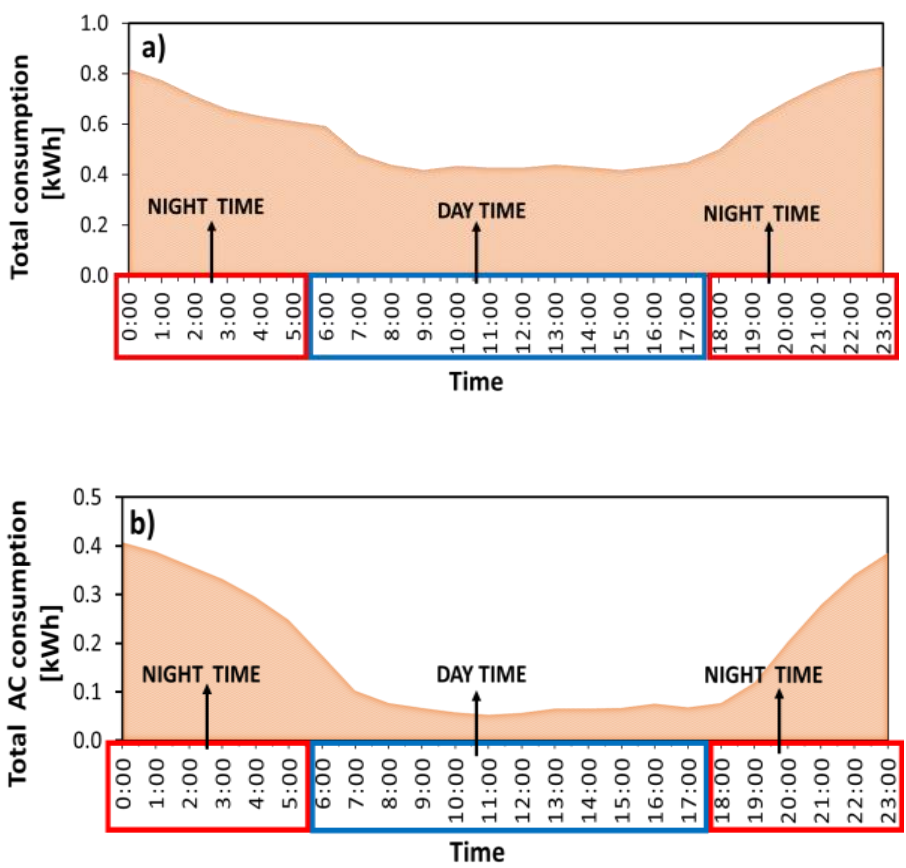

Figure 5. Time slots for, (a) Total daily energy consumption, (b) Total AC energy consumption

\subsection{Characteristics of AC load}

Figure 6 illustrates the time variations of the combined AC loads for the total dwellings of 1,5 , and 10. The electricity consumption of every minute from randomly selected dwellings was averaged and transformed into the combined AC load by concluding the coefficient of performance (COP) as 3.0, which is the minimum performance standard required in Malaysia [24]. 
a)

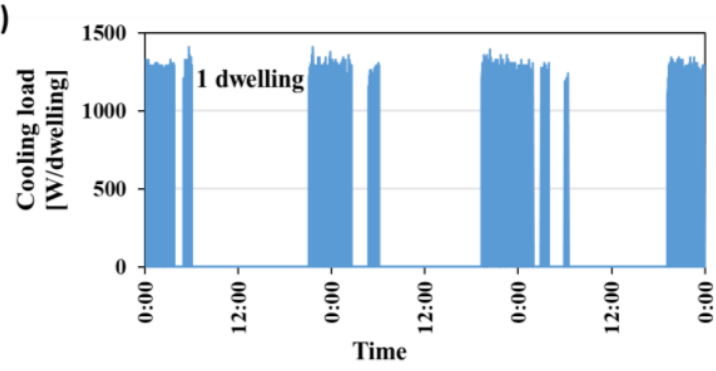

b)

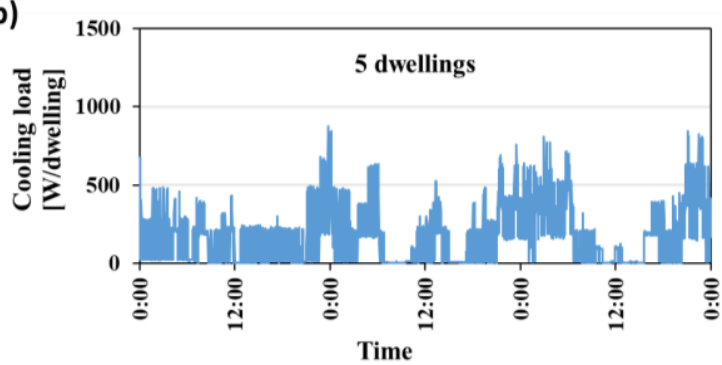

c)

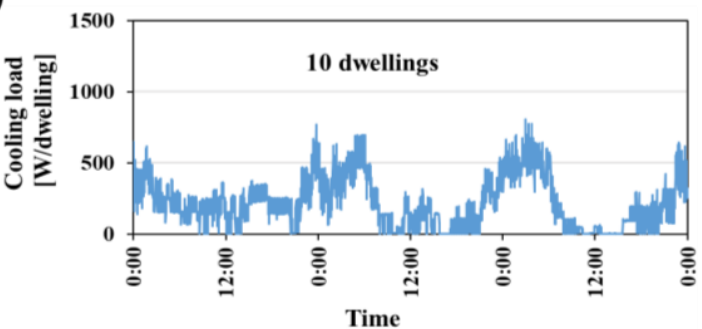

Figure 6. Time variations of the averaged AC loads for the total dwellings of, (a) 1, (b) 5, (c) 10

The monitoring data were collected from three consecutive days, from 13 to 15 March 2016. Only 10 dwellings out of 20 targeted dwellings were used for the calculation as the measurement of electricity consumption was not conducted simultaneously. This finding highlighted that the AC load of one dwelling had a high frequency and strong fluctuations due to the use of the on/off controller when the compressor operated at its maximum speed, and adjusted the indoor temperature to reach the temperature setting. When the total number of dwellings increased to 5 and 10, both short term fluctuations and peak cooling loads reduced, and long-term patterns, such as daily variation, corresponding to the various patterns of AC usage among different dwellings can be seen.

\subsection{Correlation of AC consumption with outdoor temperature}

The strength of the relationship between two variables can be evaluated using correlation coefficients equation such as the Pearson correlation coefficient (or Pearson's $r$ ) as shown in (3).

$$
r=\frac{\mathrm{n} \sum x y-\left(\sum x\right)\left(\sum y\right)}{\sqrt{\left[n \sum x^{2}-\left(\sum x\right)^{2}\right]\left[n \sum y^{2}-\left(\sum y\right)^{2}\right]}}
$$

where $n$ is number of pairs of scores, $\sum x y$ is the sum of the products of paired scores, $\sum x$ is the sum of $x$ scores, $\sum y$ is sum of y scores, $\sum x^{2}$ is the sum of squared $x$ scores and $\sum y^{2}$ is the sum of squared $y$ scores. The values can range between -1 to +1 at which means the greater the absolute value of the correlation coefficient, the stronger the relationship. In this research, this correlation coefficient is used by SPSS to measure the relationship between the total daily $\mathrm{AC}$ consumption and the mean daily outdoor temperature.

From the calculation of the correlation coefficient, all 20 dwellings with their corresponding correlation coefficient were shown in Table 1. The highest correlation coefficient is 0.52 (ID4) and the lowest is -0.10 (ID9). The AC electricity usage in most of the targeted dwellings is positively correlated with outdoor temperature, for which the correlation coefficient ranged from -0.1 to 0.5. Yoshino et al., [25] also revealed a strong correlation between the cooling energy consumption and the outdoor temperature.

Table 1. Correlation coefficient of each dwelling

\begin{tabular}{cccc}
\hline ID & Correlation coefficient & ID & Correlation coefficient \\
\hline 1 & 0.32 & 11 & 0.44 \\
2 & 0.29 & 12 & 0.23 \\
3 & 0.28 & 13 & 0.24 \\
4 & 0.52 & 14 & 0.33 \\
5 & 0.21 & 15 & 0.38 \\
6 & 0.20 & 16 & 0.42 \\
7 & 0.39 & 17 & 0.25 \\
8 & 0.14 & 18 & 0.27 \\
9 & -0.10 & 19 & 0.33 \\
10 & 0.08 & 20 & 0.48 \\
\hline
\end{tabular}




\subsection{Time of AC electricity usage increase with outdoor temperature}

The variation of electricity consumption with time is shown in Figure 7. Three targeted dwellings with the highest and lowest correlation coefficients as displayed in Figures 7(a)-(b), respectively, were selected for comparison. Figure 8(a) shows that the daily AC electricity consumption changes linearly with the usage time. This is because when the outdoor temperature is higher, the $\mathrm{AC}$ is used for a longer duration. The plot for ID20 is nonlinear because the residents tend to turn the AC on for a short time only. Nevertheless, in Figure 7(b), the graph is more scattered and does not show the same pattern as in Figure 7(a). As a result, the effect of high outdoor temperatures can lead to an increase in the AC usage time.
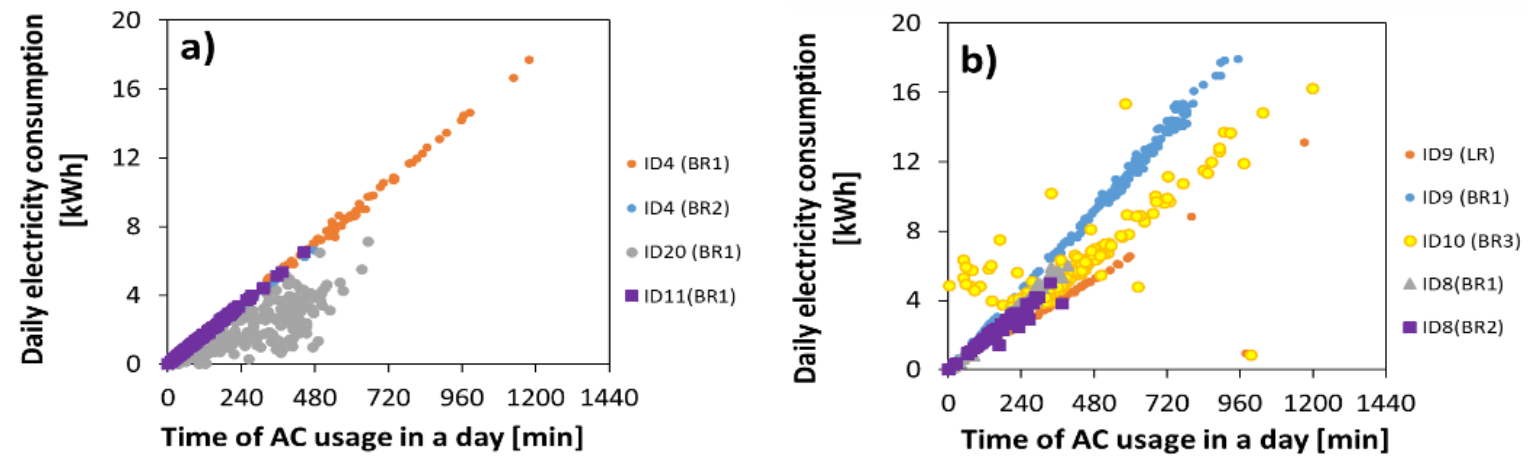

Figure 7. Change of AC consumption with the usage time, (a) Data of dwellings with 3 highest correlations, (b) Data of dwellings with 3 lowest correlations

\subsection{Pattern of AC consumption based on outdoor temperature}

The pattern of AC consumption based on outdoor temperature is shown in Figures 8. As mentioned before, the measurement was not conducted simultaneously, so the clustering process had to be split into two groups, Group 1 (ID1-ID10) and Group 2 (ID11-ID20). According to Yusof et al., [26], at a lower outdoor temperature, less work from the compressor of AC is produced as it uses less energy to maintain the temperature setup on the AC. However, the result by clustering process showed the uncommon behavior at which the energy was not corresponding with outdoor temperature. For Group 1, the uncommon behaviour is from cluster 5 . Cluster 5 has high hourly AC usage ranging from 0.8 to $1.6 \mathrm{kWh}$ when low outdoor temperatures ranging from 25 to $31^{\circ} \mathrm{C}$. This might be due to their AC performance. Higher differences between the indoor and outdoor temperatures can also be one of the reasons for this situation. The same situation is observed through cluster 4 in Group 2. Cluster 4 has a high hourly AC consumption ranging from 0.8 to $1.5 \mathrm{kWh}$ when low outdoor temperatures range from 23 to $28^{\circ} \mathrm{C}$.

a)

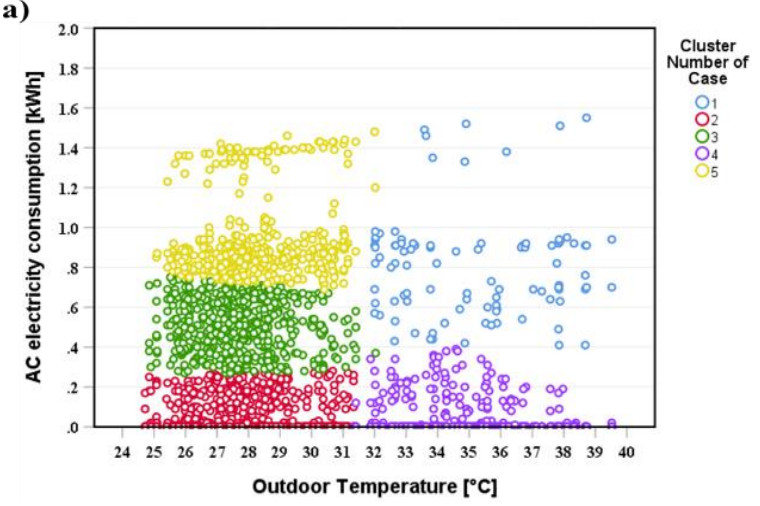

b)

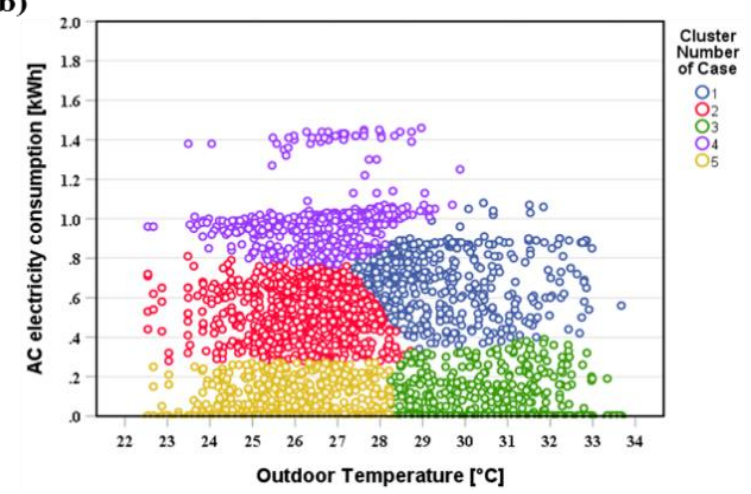

Figure 8. AC consumption pattern based on outdoor temperature for, (a) Group 1, (b) Group 2

As shown in Figure 9(a), the ID9 dwelling is the major contributor to cluster 5 with $48 \%$. Based on the interview with the occupants of the ID9 dwelling, the set point of their $\mathrm{AC}$ is $17^{\circ} \mathrm{C}$. Also, in Figure $9(\mathrm{~b})$, it can be seen that ID12 dwelling is the most dominant (95\%) in cluster 4. The ID12 dwelling has a low set point of temperature which is $16^{\circ} \mathrm{C}$. These unveil the uncommon behavior of AC consumption based on the outdoor condition. 

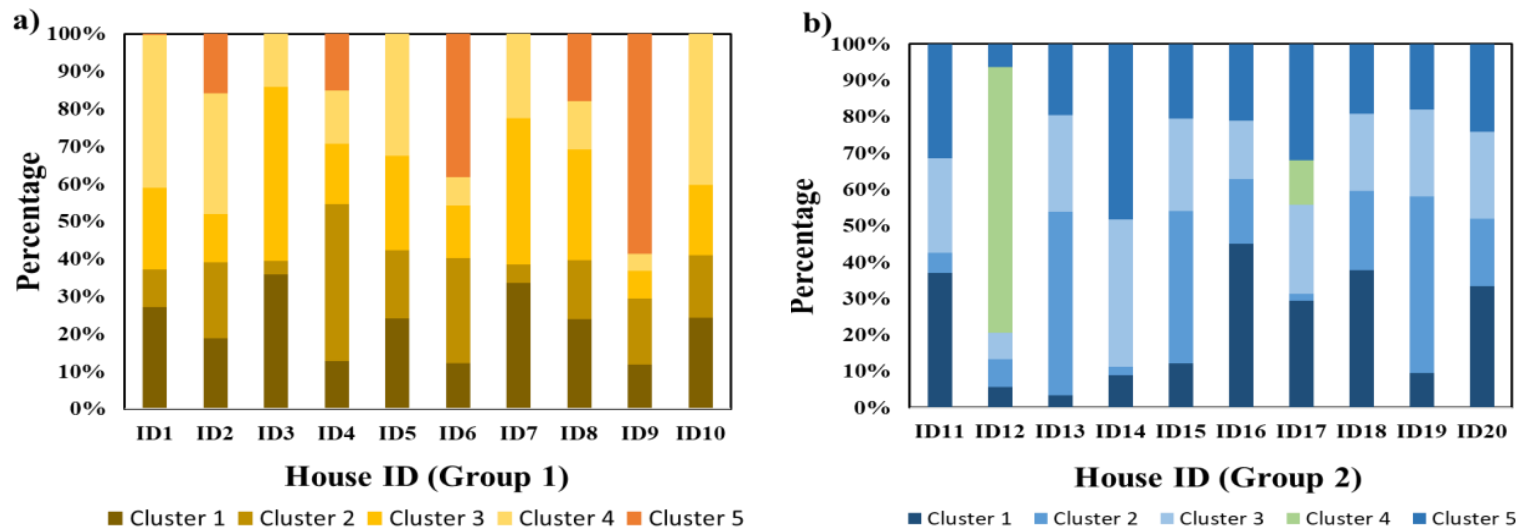

Figure 9. Percentage of cluster group in each dwelling for, (a) Group 1 and, (b) Group 2

\section{CONCLUSION}

The field measurement of 20 targeted dwellings in Kuala Lumpur and Selangor were conducted in order to investigate the occupants' energy consumption behaviour especially on the AC usage. The main outcomes are as followed; 10 selected dwellings obtained the ratio of daily AC usage of 0.9 and 5 dwellings operated the AC for five to six hours per day; From the total energy consumption, the AC usage accounted for $41 \%$ at night time and only $17 \%$ during day time. This indicated that most of the residents use the AC at night rather than at day time; Time variation of the combined AC load with the total number of 1 dwelling shows a higher frequency rather than the total number of 10 due to the use of the on/off controller when the compressor operated at its maximum speed, and adjusted the indoor temperature to reach the temperature setting; The relationship between daily total AC consumption and daily mean outdoor temperature shows that $60 \%$ from 20 targeted dwellings has a positive correlation of 0.3 to 0.5 ; The linear correlation between the AC usage time and the daily AC energy consumption proved the dependency of AC electricity consumption on the usage time; Clustering process revealed uncommon behaviour of ID9 and ID12 dwelling whereby high AC energy consumption was recorded at low outdoor temperature. The results obtained are useful for residential energy simulations in forecasting realistic AC loads, particularly in hot and humid climate such as in Malaysia.

\section{ACKNOWLEDGEMENTS}

This research was financially supported by Grant-in-Aid from the Research University Grant (01M46) from Universiti Teknologi Malaysia. Our sincere appreciation is extended to Mohd Zubaidi, Siti Sara Nursakinah and Nassir Ranjbar for their contribution in data collection.

\section{REFERENCES}

[1] "Malaysia Energy Statistics Handbook," Suruhanjaya Tenaga (Energy Commission), 2017.

[2] “2015 Malaysia Eenrgy Statistics Handbook,” Suruhanjaya Tenaga (Energy Commission), 2015.

[3] W. S. W. Abdullah, M. Osman, M. Z. A. Ab Kadir, and R. Verayiah, "The potential and status of renewable energy development in Malaysia," Energies, vol. 12, no. 12, pp. 1-16, 2019.

[4] C. K. Das, O. Bass, G. Kothapalli, T. S. Mahmoud, and D. Habibi, "Overview of energy storage systems in distribution networks: Placement, sizing, operation, and power quality," Renewable and Sustainable Energy Reviews, vol. 91, pp. 1205-1230, Aug. 2018.

[5] N. Ranjbar, S. A. Zaki, N. M. Yusoff, and A. Hagishima, "Time series data analysis of household electricity usage during el-nino in Malaysia," Chemical Engineering Transactions, vol. 56, pp. 379-384, Jan. 2017.

[6] Hiromi Habara, Rakuto Yasue, and Yoshiyuki Shimoda, "Survey on the occupant behaviour relating to window and air-conditioner operation in the residential buildings," in 13th Conference of International Building Performance Simulation Association, pp. 2007-2013, 2013.

[7] X. Ren, D. Yan, and C. Wang, "Air-conditioning usage conditional probability model for residential buildings," Building and Environtment, vol. 81, pp. 172-182, Nov 2014.

[8] V. Fabi, S. P. Corgnati, R. V. Andersen, M. Filippi, and B. W. Olesen, "Effect of occupant behaviour related influencing factors on final energy end uses in buildings," Proceedings of the Climamed, vol. 11, pp. 1-17, 2011.

[9] H. Zhou, L. Qiao, Y. Jiang, H. Sun, and Q. Chen, "Recognition of air-conditioner operation from indoor air temperature and relative humidity by a data mining approach," Energy and Buildings, vol. 111, pp. 233-241, 2016.

[10] S. Chen, W. Yang, H. Yoshino, Mark. D. Levine, K. Newhouse, and A. Hinge, "Definition of occupant behavior in 
residential buildings and its application to behavior analysis in case studies," Energy and Buildings, vol. 104, pp. 1-13, Oct 2015.

[11] K. X. Perez, W. J. Cole, J. D. Rhodes, A. Ondeck, M. Webber, M. Baldea, And T. F. Edgar, "Nonintrusive disaggregation of residential air-conditioning loads from sub-hourly smart meter data," Energy and Buildings, vol. 81, pp. 316-325, Oct 2014.

[12] N. A. Hisham, S. A. Zaki, A. Hagishima, and N. Md. Yusoff, "Load and household profiles analysis for airconditioning and total electricity in Malaysia," Knowledge E Enriching, Engaging, Empowering, pp. 773-786, 2019.

[13] N. Aqilah, S. A. Z. S. Salim, A. Hagishima, N. M. Yusoff, and F. Yakub, "Time series data measurement on electricity consumption for selected domestic appliances in typical terrace house of Malaysia," Bulletin of Engineering and Informatics, vol. 8, no. 3, pp. 1145-1153, 2019.

[14] Youguo Li and Haiyan Wu, "A clustering method based on K-Means algorithm," Physics Procedia, vol. 25, pp. 1104-1109, 2012.

[15] F. Wang, K. Li, K. Li, L. Zhou, H. Rui, J. Contreas, M. Shafie-Khah, and J. P. Catalão, "Daily pattern prediction based classification modeling approach for day-ahead electricity price forecasting," International Journal of Electrical Power \& Energy System, vol. 105, pp. 529-540, 2019.

[16] H. Cai, S. Shen, Q. Lin, X. Li, and H. Xiao, "Predicting the energy consumption of residential buildings for regional electricity supply-side and demand-side management," in IEEE Access, vol. 7, pp. 30386-30397, 2019.

[17] S. Bimenyimana, G. N. O. Asemota, P. J. Ihirwe, and L. Li, "Clustering residential electricity consumption: A case study," EEET '18: Proceedings of the 2018 International Conference on Electronics and Electrical Engineering Technology, pp. 44-51, Sept. 2018.

[18] M. Z. Hossain, Md. N. Akhtar, R. B. Ahmad, and M, Rahman, "A dynamic K-means clustering for data mining," Indonesian Journal of Electrical Engineering and Computer Science (IJEECS), vol. 13, no. 2, pp. 521-526, 2019.

[19] Ali Al-Wakeel, Jianzhong Wu, and Nick Jenkins, "K-means based load estimation of domestic smart meter measurements," Applied Energy, vol. 194, pp. 333-342, May 2017.

[20] B. Nepal, M. Yamaha, H. Sahashi, and A. Yokoe, "Analysis of building electricity use pattern using k-means clustering algorithm by determination of better initial centroids and number of clusters," Energies, vol. 12, no. 12, pp. 1-17, 2019.

[21] Nicolás Carbonare, Thibault Pflug, and Andreas Wagner, "Clustering the occupant behavior in residential buildings: A method comparison,” Bauphysik, vol. 40, no. 6, pp. 427-433, 2018.

[22] J. Wu, C. Liu, H. Li, D. Ouyang, and J. Cheng, "Residential air-conditioner usage in China and efficiency standardization," Energy, vol. 119, pp. 1036-1046, Jan. 2017.

[23] T. Kubota, S. Jeong, D. H. C. Toe, and D. R. Ossen, "Energy consumption and air-conditioning usage in residential buildings of Malaysia," 11th International Conference on Sustainable Environmental Architecture (SENVAR), vol. 17, no. 3, pp. 61-69, 2011.

[24] M. F. Othman, H. Abdullah, N. A. Sulaiman, and M. Y. Hassan, "Performance evaluation of an actual building airconditioning system," IOP Conference Series: Materials Science and Engineering, vol. 50, pp. 1-8, July 2013.

[25] H. Yoshino, J. C. Xie, T. Mitamura, T. Chiba, H. Sugawara, K. L. Hasegawa, K. Genjo, and S. Murakami, "A two year measurement of energy consumption and indoor temperature of 13 houses in a cold climatic region of Japan," Journal of Asian Architecture and Building Engineering, vol. 5, no. 2, pp. 361-368, Oct. 2018.

[26] M. H. Yusof, S. M. Muslim, M. F. Suhaimi, and M. F. Basrawi, "The effect of refrigerant charge and outdoor temperature on the condenser and evaporator of a split-unit type air conditioner using R22 refrigerant," MATEC Web of Conferences, vol. 225, p. 02013, Nov 2018.

\section{BIOGRAPHIES OF AUTHORS}

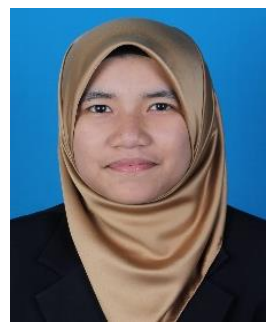

Naja Aqilah Hisham received her Bachelor of Engineering in Electronic System Engineering from Universiti Teknologi Malaysia in 2017. She is currently a postgraduate student pursuing her master's degree under the supervision of Dr Sheikh Ahmad Zaki in Malaysia Japan International Institute of Technology (MJIIT), UTM. Her research concerns with the analysis of electricity consumption in the residential sector in Malaysia.

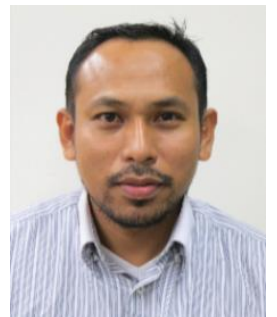

Sheikh Ahmad Zaki Shaikh Salim obtained his Ph.D in Energy and Environmental Engineering from Kyushu University in 2011. Currently, he is an associate professor at the Department of Mechanical Precision Engineering, Malaysia-Japan International Institute of Technology (MJIIT), Universiti Teknologi Malaysia (UTM). His research is mainly focused on urban climatology, building and environmental engineering, and wind engineering. 


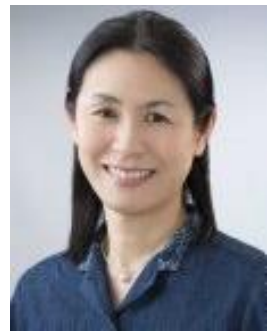

Aya Hagishima has been working as an academic staff member of Kyushu University, Japan since 2005. She is currently a professor at the Department of Energy and Environmental Engineering, Interdisciplinary Graduate School of Engineering Sciences (IGSES). She received a doctorate degree in engineering in 2002. Her main research topics are within the disciplines of microclimatology, wind engineering, and building environmental engineering.

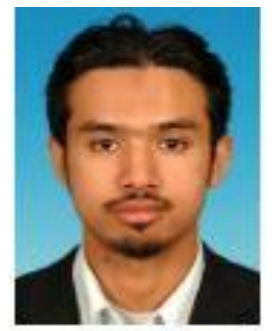

Fitri Yakub received his diploma in Mechatronics Engineering and bachelor's degree in Electronic Engineering from University of Technology Malaysia in 2001 and 2006, respectively. $\mathrm{He}$ obtained Master of Science in Mechatronics Engineering from the International Islamic University Malaysia in 2011. He received his doctorate degree from Tokyo Metropolitan University in 2015. He has been a staff member at Malaysia-Japan International Institute of Technology since 2012. His field of research interest includes intelligent control, automatic and robust control, and motion control systems.

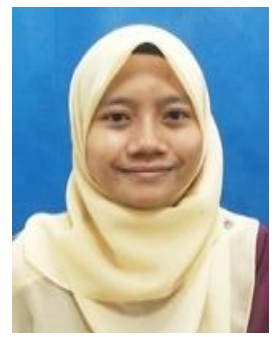

Hafizah Farhah Saipan Saipol received her bachelor's degree in Industrial Mathematics and obtained her Ph.D in Mathematics from Universiti Teknologi Malaysia in 2016. She is now working as a lecturer under Department of Management Technology in Malaysia-Japan International Institute of Technology, UTM. Her field of research includes scientific computing and numerical simulation. 